Arkivoc

Free to Authors and Readers
A Platinum Open Access Journal

for Organic Chemistry
Review

Arkivoc 2021, part vii, 66-78

\title{
Industrial applications of organic polyiodides
}

\author{
Tatsuo Kaiho
}

Godo Shigen Co. Ltd. CIRIC, Chiba University

1-33 Yayoicho, Inage-Ku, Chiba 263-8522 Japan

Email: tkaiho0209@gmail.com

Received 07-04-2021

Accepted 08-24-2021

Published on line 09-11-2021

\section{Abstract}

The major uses of iodine compounds are X-ray contrast media, disinfectants, pharmaceuticals, catalysts, and polarizers. Some of those applications are related to organic polyiodides. Polyiodides belong to the type of compounds known as hypervalent iodine, which violate the Lewis octet rule. This review summarizes various industrial applications of organic polyiodide compounds such as 1) Ion exchange resin (IER) iodine, Povidone (PVP) iodine, and Amylose iodine (disinfectants), 2) Polyvinyl alcohol (PVA) iodine and Bio-amylose iodine (polarizing film) and 3) Bio-amylose iodine (precursor of graphitic film).

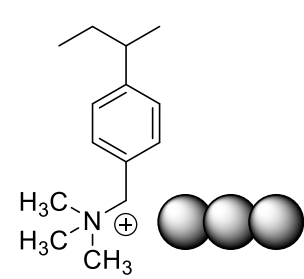

IER iodine

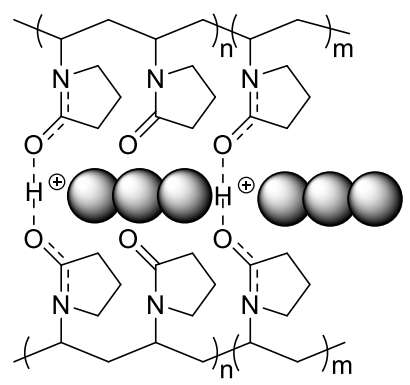

PVP iodine

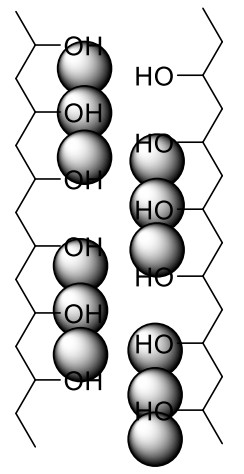

PVA iodine

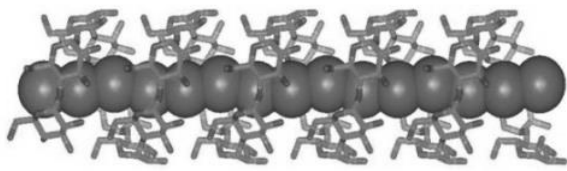

Bioamylose iodine

Keywords: Polyiodide, triiodide, ion exchange resin, povidone, polyvinyl alcohol, amylose 


\section{Table of Contents}

1. Introduction

2. Iodine production and polyiodide

3. Ion exchange resin iodine

4. Povidone and polyiodide

5. Bioamylose polyiodide

6. Polarizing film and polyiodide

7. Dye-Sensitized Solar Cell (DSSC) and polyiodide

8. Low-density graphitic films and polyiodide

Conclusions

Acknowledgements

References

\section{Introduction}

The linear geometric structure of triiodide $\left(\mathrm{I}_{3}^{-}\right)$was determined for the first time in 1935 by Mooney, who carried out X-ray analysis on ammonium triiodide. ${ }^{1-3}$ The triiodide anion belongs to the type of compounds known as hypervalent, which violate the Lewis octet rule. Various industrial applications of polyiodide compounds are summarized in this review. 1) lodine is isolated in the form of polyiodide from natural gas brine using ion exchange resin in Japan. 2) Ion exchange resin iodine, Povidone-lodine, and amylose iodine, which contain iodine as triiodide, have a wide range of antimicrobial activities bacteria, viruses, parasites and mold. 3) Polarizing film is prepared primarily using triiodide to stain polyvinyl alcohol (PVA) or bio-amylose. 4) Bio-amylose polyiodide complex is a novel precursor of low-density graphitic film.

\section{2. lodine Production and Polyiodide ${ }^{4}$}

lodine is produced from natural gas brine or oil brine in Japan. Brine containing 100-150 ppm iodine as iodide ions is pumped up from the underground (500-2000 $\mathrm{m}$ ) in Japan. Sand and impurities in brine are removed by settling or filtering. Brine is acidified with sulfuric acid, and then oxidized by chlorine or sodium hypochlorite to liberate the iodine. Two methods are used to purify the iodine: (i) the blowing out method, and (ii) the ionexchange method. In the ion-exchange method, iodide is partially oxidized to liberate iodine, which reacts with iodide ions to form triiodide ions. The triiodide ions in brine (3\% salt water) are selectively adsorbed on an anionic-exchange resin (Amberlite) (Figure 1). The resin is transferred to the recovery column, where triiodides on the resin are reduced with sodium bisulfite aqueous solution and eluted. The iodide-rich eluate is continuously oxidized with chlorine gas to precipitate molecular iodine. The wet iodine is purified by melting under concentrated sulfuric acid to remove water and organic contaminants. The fused iodine is flaked or prilled, and packaged as the product (Figure 2). 


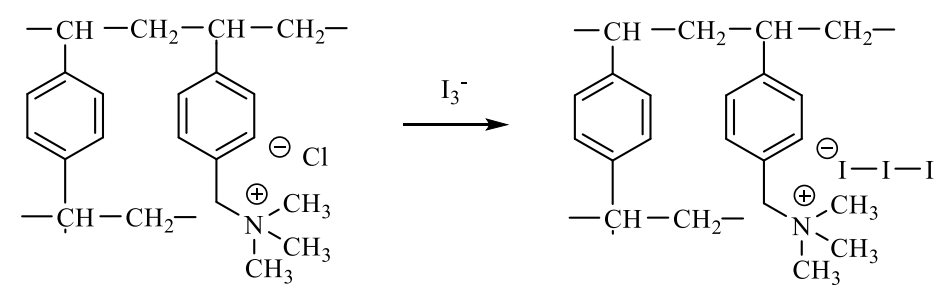

Figure 1. Adsorption of iodine on ion exchange resin.

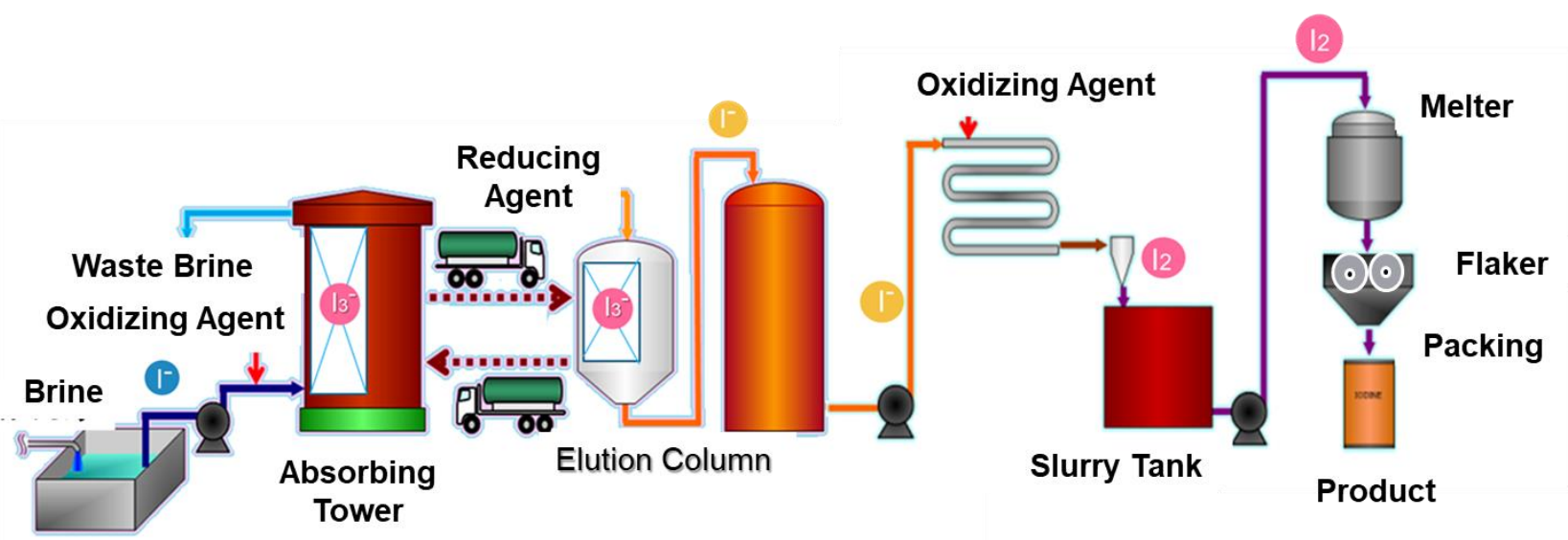

Figure 2. lodine production by ion exchange resin method.

\section{Ion Exchange Resin lodine}

lodine has been known to have bactericidal effects since ancient times. However, due to its sublimability (the ability to change directly from the solid state to the vapor state), there were restrictions on its scope of use. Ion exchange resin (IER) iodine is a unique solid disinfectant which provides a solution to the above problem. lodine absorption resin is characterized by an ionic bond between the basic anion ion-exchange resin (IER) and quaternary ammonium ion as a functional group (Amberlite) (Figure 3). Under normal conditions, iodine is rarely released in water. When target ions, which have a higher tendency to ionize than iodine itself, approach the IER surface, force which induces iodine ion exchange is applied, resulting in the release of iodine ions. As a result, negative bacteria or viruses which come in contact with the IER surface are exterminated by the oxidative effect of the free iodine. Furthermore, as time passes, iodine penetrates the cell from the cell membrane and oxidizes inside of the cell. In this way, IER iodine is able to instantly eliminate microbes such as bacteria, viruses, parasites and mold. Specifically, iodine is effective against SARS, influenza viruses, anthrax, Newcastle disease viruses and Aspergillus niger, which seldom becomes drug resistant to iodine. 


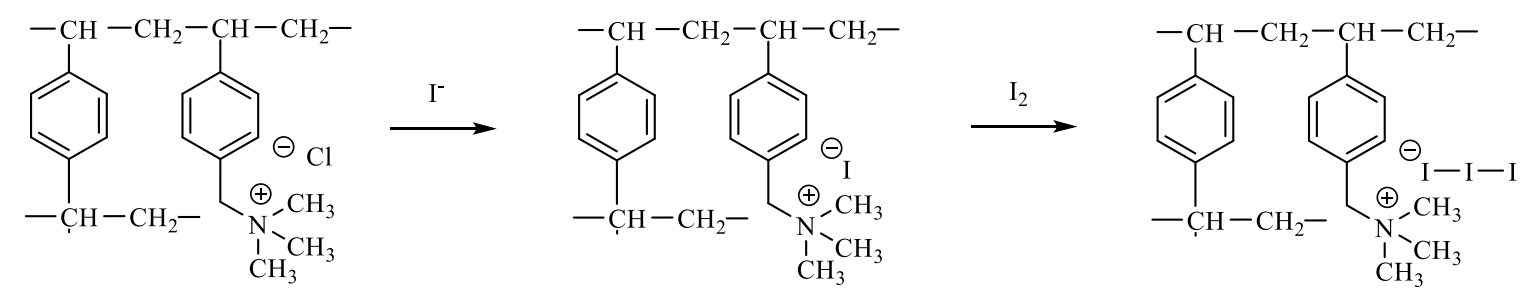

Figure 3. Preparation of ion exchange resin iodine.
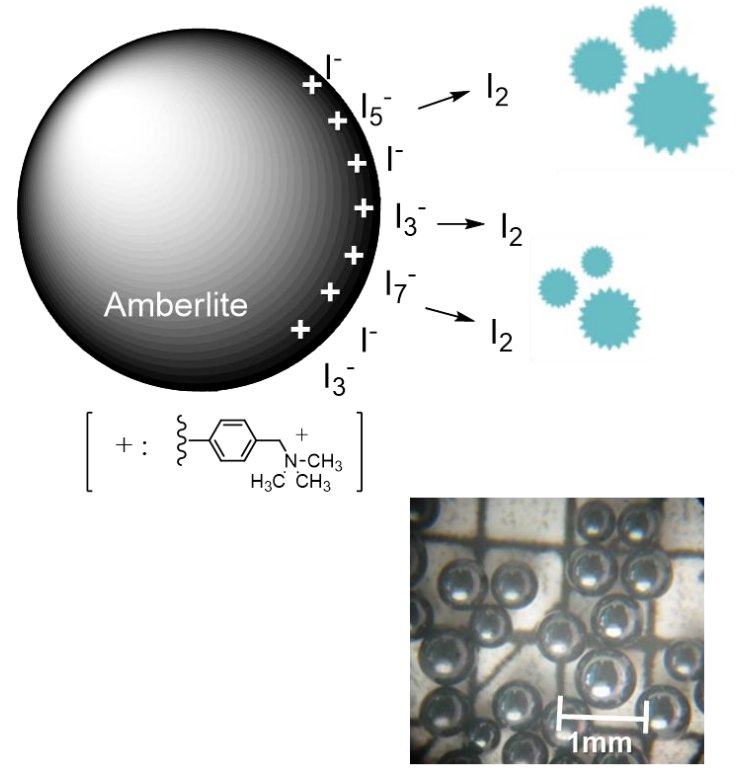

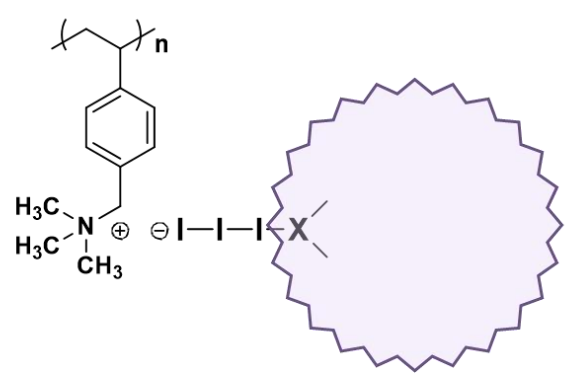

Bacteria : $\mathrm{X}=\mathrm{N}, \mathrm{O}, \mathrm{S}$

Demand Release Disinfectant

Figure 4. Demand release disinfectant.

In addition, IER iodine is effective against weaponized chemical gases, breaking down mustard gas, VX gas, etc. During times of war and chemical terrorism, IER iodine is used in gas masks. ${ }^{7}$ The shape of the IER iodine is normally a prill bead approximately $0.5 \sim 1 \mathrm{~mm}$ (Figure 4). This is due to the fact that the larger the surface area which comes into contact with the microbes, the more effective the extermination. IER can be used as a resin particle, or mixed with plastic (polypropylene, polyethylene, nylon, etc.) or fibers such as nonwoven fabric. It is used in a variety of ways in material used for sterilization of water and air containing bacteria and viruses.

A special water recycling system is used at the International Space Station (ISS) to produce pure distilled water from condensed water, the urine of crew members, and their cleaning/washing water. This distilled water, along with other wastewater collected from the spacecraft, is combined to ultimately be processed in the water treatment device to create drinking water for crew members. lodine adsorption resin is used in this water treatment device. Similar to adding chlorine to household drinking water, iodine treatment is carried out to inhibit the growth of microbes. lodine is used instead of chlorine because solid IER iodine is far easier to transport in orbit than chlorine gas. ${ }^{8}$ 


\section{Povidone and Polyiodide}

Sterilizing agents commonly used in hospitals include benzalkonium chloride, chlorohexidine gluconate and povidone iodine. Among these, povidone iodine has the longest history of use. Povidone iodine comes in forms such as $10 \%$ povidone iodine solution, $7.5 \%$ povidone iodine scrub, $10 \%$ povidone iodine ethanol solution, $0.5 \%$ povidone iodine ethanol hand rub formulation, $10 \%$ povidone iodine gel and $5 \%$ povidone iodine cream.

Povidone iodine is effective for gram-positive bacteria, gram-negative bacteria, tubercle bacilli, fungi, viruses and clostridium bacteria, covering a broad antimicrobial spectrum. It is an excellent antiseptic that is hypoallergenic and with relatively few side effects. It can be applied to surgical sites, wounds, as well as mucosa such as the oral cavity and vagina. It is also effective against AIDS and hepatitis B viruses. When povidone iodine is applied to the skin to form a film, a prolonged sterilizing effect can be achieved. However, since it evaporates relatively quickly and loses effect, it is inferior to other iodine agents.

Povidone iodine is a water soluble complex in which iodine is bonded with the carrier polyvinyl pyrrolidone (PVP) (Figure 5). Effective iodine contained in $1 \mathrm{~g}$ of povidone iodine is $100 \mathrm{mg}$. For example, a $10 \%$ povidone iodine solution has $1.0 \%$ effective iodine. Povidone iodine maintains a state of equilibrium in the solution and as the free iodine concentration in the solution decreases, iodine is gradually released. Hence, when povidone iodine solution is diluted to around $0.1 \%$, the retention force of the carrier is the lowest and the free iodine concentration is the highest (approx. $25 \mathrm{ppm}$ ). However, since povidone iodine is easily absorbed into the body when used on burn sites, the vagina and oral cavity, side effects such as thyroid metabolic abnormality may occur when used for an extended period time or over a large area. Caution is needed regarding its use.

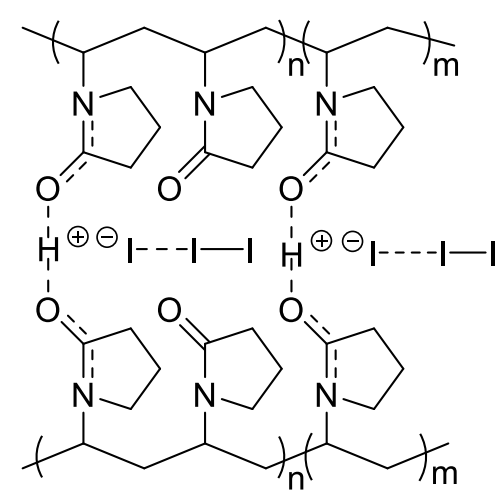

Figure 5. Povidone iodine.

\section{Bioamylose Polyiodide}

Amylose is found in natural starch at a concentration of approximately $20 \%$, but there is no effective way of separating it. As a result, no progress has been seen in its industrial use. However, enzymatic synthesized amylose(ESA) is a straight chain, unlike natural amylose. This amylose can be synthesized of any given molecular weight in a very narrow molecular weight distribution. These macromolecules are called bioamylose. Bio-amylose has a spiral structure (host material) and captures other materials (guest materials) in its cavity. Furthermore, by creating an "amycel" by kneading amylose into rayon, the inclusion action of 
amylose can be provided to a fiber or sheet (Figure 6). lodine included in amycel is effective for Influenza Virus (Figure 7), Escherichia coli 0-157 and methillin-resistant Staphylococcus aureus (MRSA).

By circulating air through the iodine-including amycel filter, bacteria and viruses in the air can be substantially inactivated. An odor-eliminating effect on malodorous substances such as ammonia and methyl mercaptan can also be observed. lodine-including amycel consumes iodine as the functions are performed, and its dark purple color gradually fades. This is an indicator of the sustainability of the effect, and functions have a fixed period of performance. The color of the material can be used to gauge effectiveness of the functions. lodine-including amycel is biodegradable and an environmentally-circulating material (Figure 7).
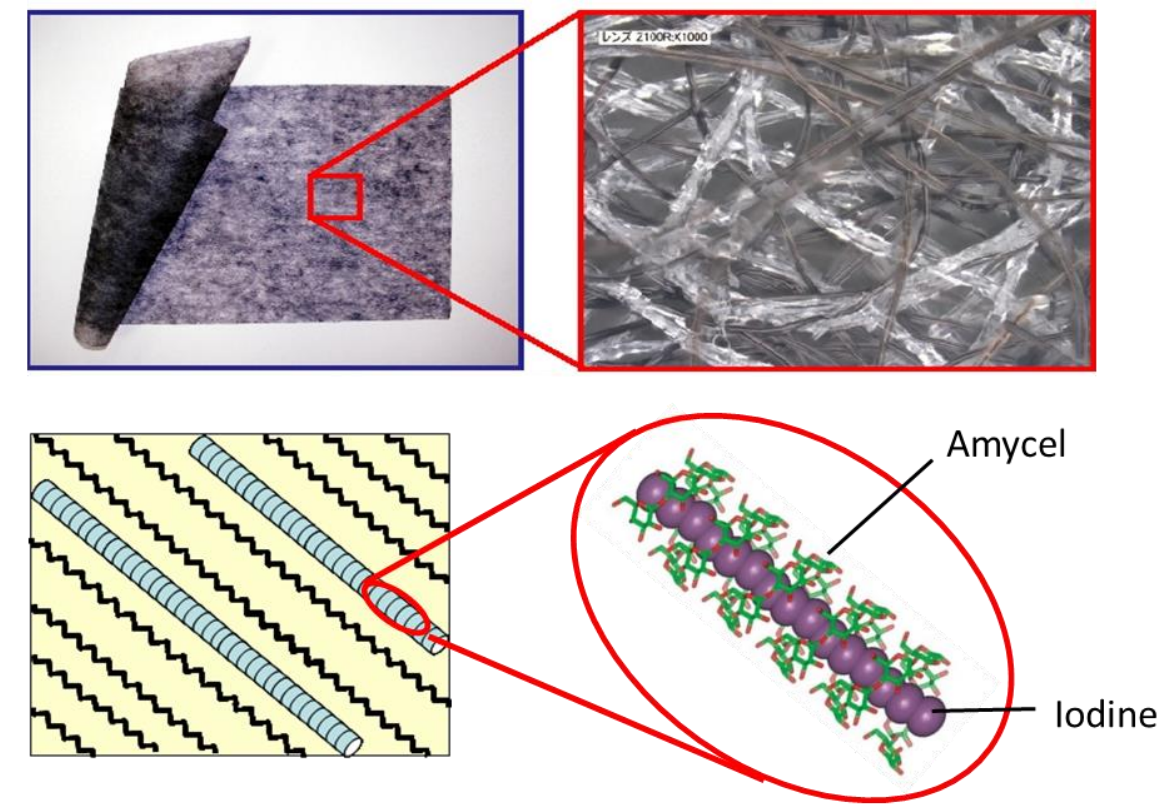

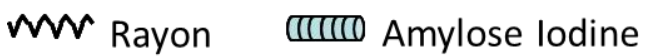

Figure 6. Bio-amylose iodine.

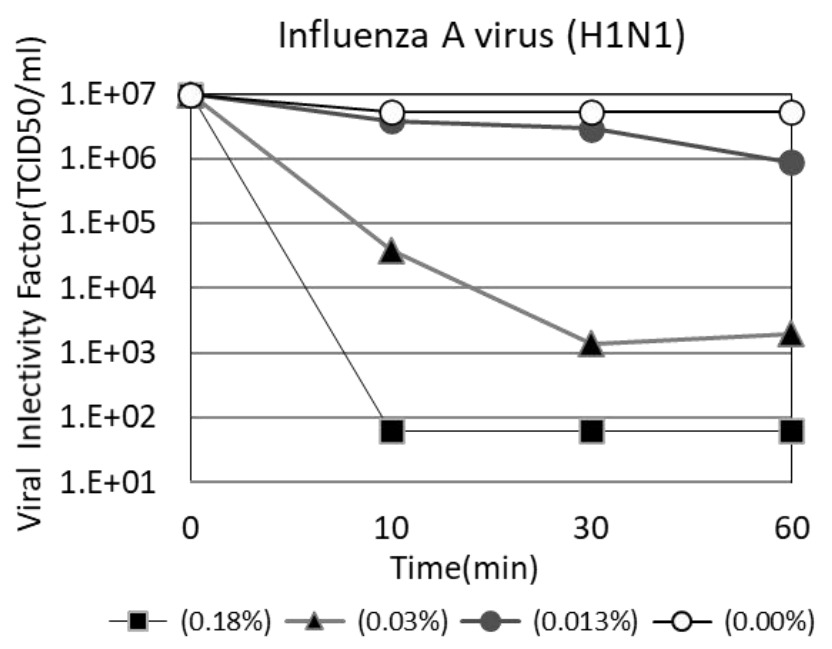

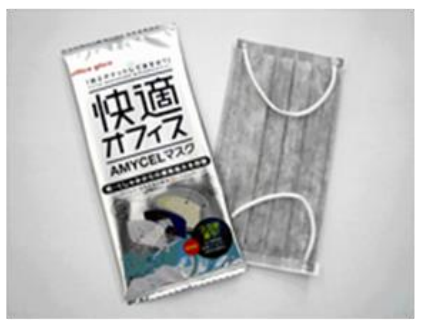

Amycel lodine Mask

lodine Conc. In Amycel lodine

Figure 7. Amycell iodine mask. 


\section{Polarizing Film and Polyiodide}

Polarizing film (film with polarizing performance) is made primarily using iodine or dye to stain polyvinyl alcohol (PVA). The film is stretched and oriented to allow only polarized light in a fixed vibration direction to pass through. In particular, iodine-type polarizing film has superior polarizing performance compared to dyetype polarizing film, and is used widely in LCD televisions and mobile phone screens. However, under high temperature conditions, the dye-type is considered to be more effective.

lodine-type polarizing film used in LCDs is produced as follows: First, a polyvinyl alcohol (PVA) film which has expanded in water is soaked in an iodine/potassium iodide solution. Next, it is treated with boric acid, and then stretched, rolled and dried. As a result, a polarizing film with polyiodide ions $\left(I_{3}^{-}, I_{5}{ }^{-}\right)$neatly aligned between the PVA molecule chain in the stretching direction is created (Figure 8).

Examining this film in detail, the polyiodide ions $\left(\mathrm{I}_{3}{ }^{-}, \mathrm{I}_{5}{ }^{-}\right)$are found to be sandwiched between the surface of the crystal part of the PVA with a polymerization degree of 2400 and the non-crystal part of the PVA molecule chain, and the structure of both ends is closed and fixed with boric acid crosslinking (left middle diagram).

The LCD principle is shown in the diagram. When a twisted liquid crystal is inserted between 2 sheets of polarizing filters. The polarizing direction of the filters intersects at right angles so light does not pass through. Light coming in from below is twisted 90 degrees along the gap of the liquid crystal molecules, allowing light to pass through the filter above (passage of light). When voltage is applied, the liquid crystal molecules are aligned and untwist. Light coming in from above travels upward and cannot pass through the filter above (light is blocked). In other words, voltage is used as the trigger, and the liquid crystal assumes the role of an optical shutter (Figure 9). Bio-amylose polyiodide complex has the same polarizing performance with PVA polyiodide (Figure 10). These iodine-type polarizing films are essential in modern information equipment.

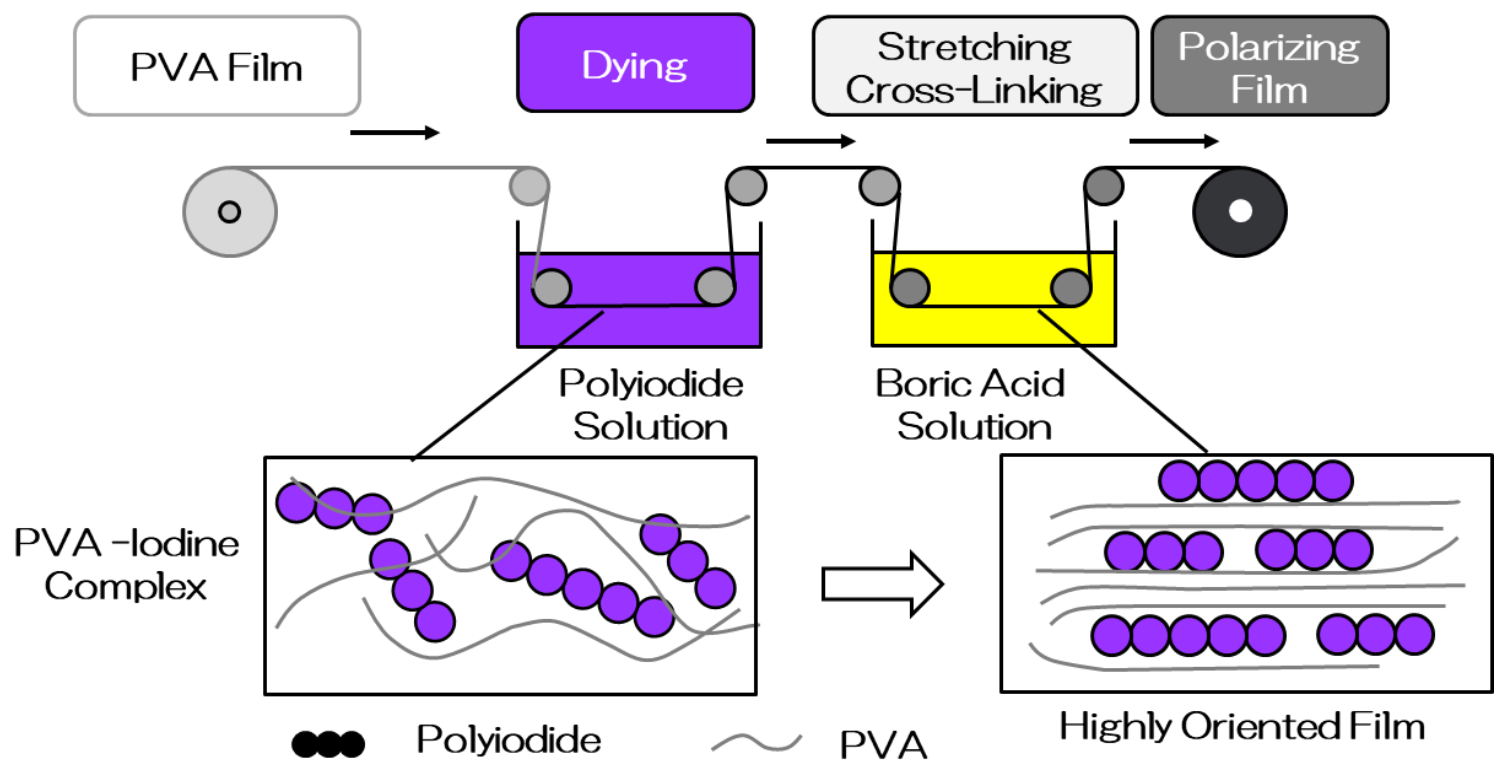

Figure 8. Production method of polarizer. 


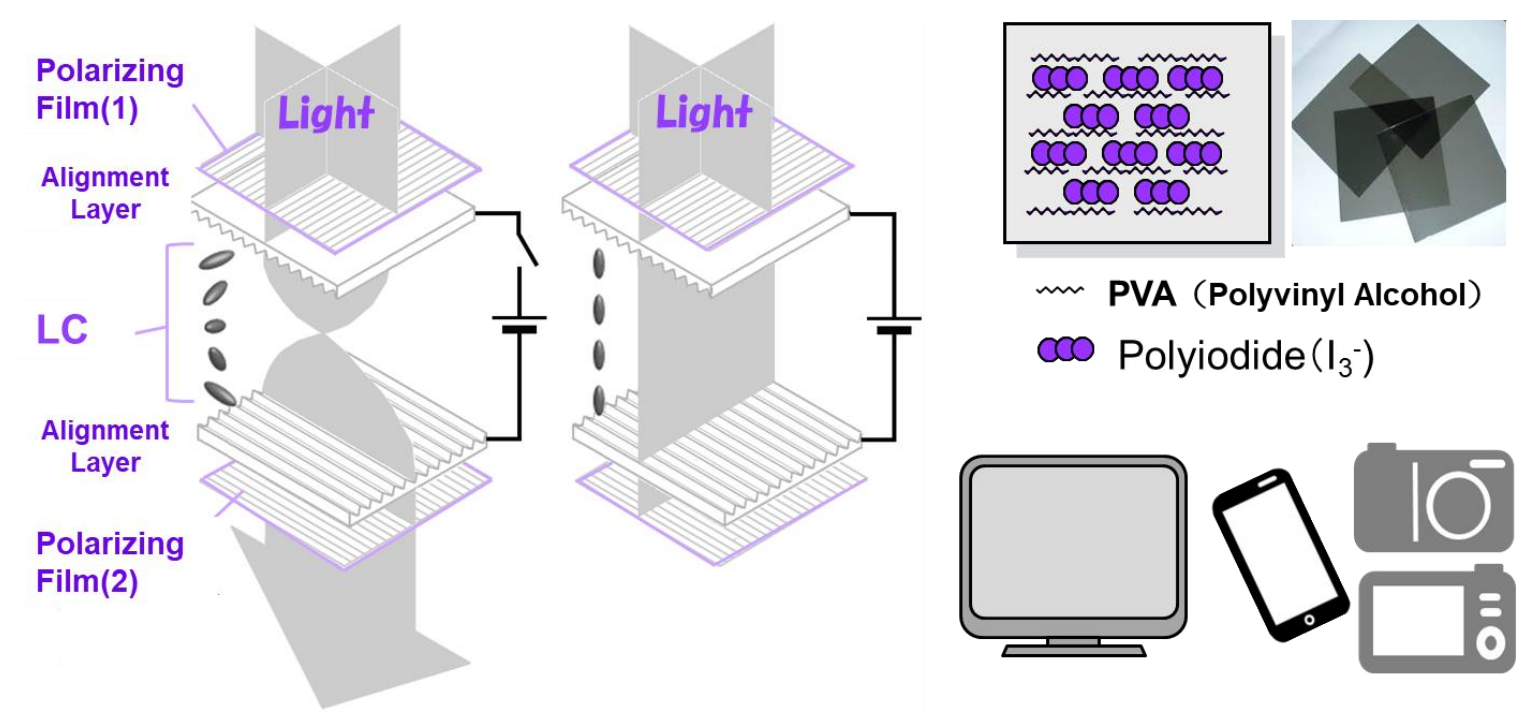

Figure 9. LCD and Polarizing film.

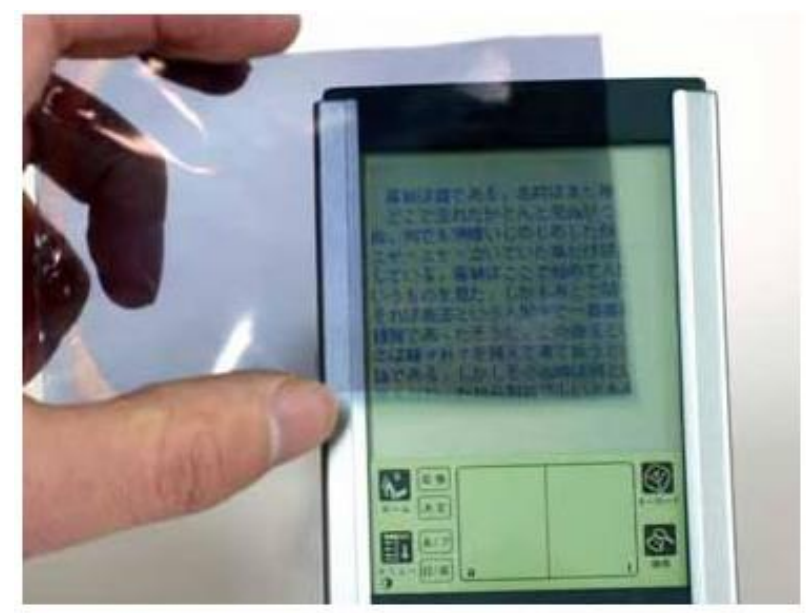

Figure 10. Bio-amylose iodine /Polarizing film.

\section{Dye-Sensitized Solar Cell (DSSC) and Polyiodide}

In 1991, Professor Gratzel of the Swiss Federal Institute of Technology in Lausanne, Switzerland, developed dye-sensitized solar cells comprised of electrodes where a ruthenium metal complex is adsorbed onto porous titanium oxide, iodine-based electrolytic solution and platinum counter electrodes. This triggered active research worldwide, and now, improvements have been led to a conversion efficiency exceeding $11 \%$.

The action concept of dye-sensitized solar cells is shown in Figure 11. First, the dye absorbs sunlight and becomes excited. Next, the electrons are transferred to titanium dioxide, generating electromotive force. The dye receives the electrons from iodide ions in the electrolytic solution and returns to the ground state. The triiodide ions generated in this process are reduced at the counter electrodes. Through this series of chemical reactions, an electric current is created.

The typical manufacturing process for solar cells is described below. First, a paste containing dispersed, fine titanium oxide particles is applied to a substrate with a transparent conductive film, and then baked 
$\left(400^{\sim} 500^{\circ} \mathrm{C}\right.$ ) to create a porous titanium oxide film. This film is then immersed in a dye solution so that the dye is adsorbed to the titanium oxide surface. Next, an iodine-based electrolytic solution is injected between the counter electrodes to seal the surroundings. Since the production process of dye-sensitized solar cells does not require a vacuum or high temperature processing, they can be manufactured at a lower cost compared to conventional silicon-based solar cells. In addition, there is greater freedom in choosing the color and process shape design as well as the added option of combining various dyes to adjust the absorption wavelength. Moreover, dye-sensitized solar cells can be generated in dim morning and late afternoon light as well as by artificial room lighting.

We have prepared quasi-solid dye-sensitized solar cells (QDSCs) consisting of amylose/porous $\mathrm{Al}_{2} \mathrm{O}_{3}$ film/ionic liq. films (Am-Al/IL film). ${ }^{14}$ The surface of straight nanopores in the $\mathrm{Al}_{2} \mathrm{O}_{3}$ film was modified with amylose and these nanopores were filled with ionic-liq.-type electrolytes. The ionic liq. did not leak from these nanopores of the film. The photovoltaic performance of the QDSC consisting of Am-Al/IL films was almost the same as that before the solidification, despite that the film was occupied with $50 \%$ of electrochem. inactive $\mathrm{Al}_{2} \mathrm{O}_{3}$ wall. It was found that the iodine was adsorbed on the straight wall of Am-Al films and the apparent diffusion coefficient of triiodide species was almost the same as that in the parent liquid electrolyte. From these results, we propose QDSC structures consisting of two-carrier-density layers $\left(I^{-} / I_{3}^{-}\right)$ with low and high carrier concentrations for high-efficiency cells. A bulk area between a counter electrode and a $\mathrm{TiO}_{2}$ electrode is occupied with a high-carrier-density medium $\left(\mathrm{I}^{-} / \mathrm{I}_{3}^{-}\right)$, and $\mathrm{TiO}_{2}$ nanopores are filled with a low-carrier-density medium $\left(\mathrm{I}^{-} / \mathrm{I}_{3}^{-}\right)$. The former increases the conductivity and the latter suppresses the back electron transfer from the $\mathrm{TiO}_{2}$ layer to redox species (Figure 11).

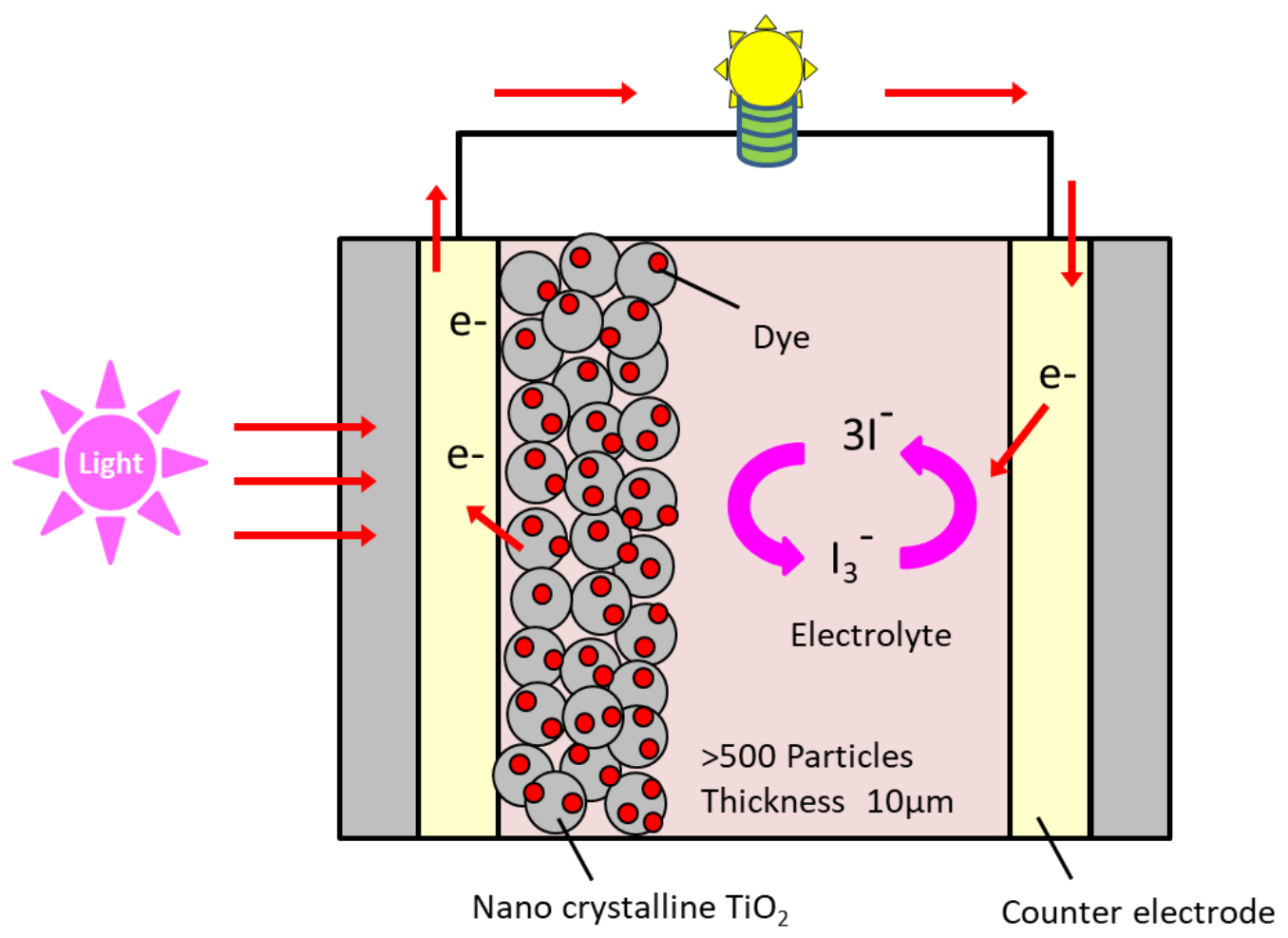

Figure 11. Dye-sensitized solar cells (DSSC). 


\section{Low-Density Graphitic Films and Polyiodide.}

Amylose is a linear polymer made up of glucose units with $\alpha-1,4$ linkages. It forms a helical structure owing to intrachain hydrogen bonding, where one helical pitch corresponds to six $\alpha$-glucose units. Amylose is also known to exhibit a so-called iodo-starch reaction in which the color of amylose changes from red to blue depending on the helical chain length because iodine molecules penetrate into the amylose coil to form charge transfer complexes between the amylose coil and $\mathrm{I}_{3}{ }^{-}$or $\mathrm{I}_{5}{ }^{-}$. The use of iodine as a stabilizer for producing carbon products from potato starch and chitosan was reported by Miyajima and co-workers. However, it is well established that natural amylose has a slightly branched structure .

We have developed a novel approach for preparing low-density graphitic films using iodine-doped Bioamylose with strictly controlled molecular weights as carbonization precursors (Table 1). All of the iodinedoped Bio-amylose retained their film structures and morphologies, even after the heat-treatment at $800{ }^{\circ} \mathrm{C}$ and $2600{ }^{\circ} \mathrm{C}$ (Figure 12). Therefore, iodine doping plays an indispensable role in retaining film structure and morphology during the carbonization of Bio-amylose films (Figure 13). It was also elucidated that the carbonization yields of the Bio-amylose films can be controlled by changing the conditions of iodine doping process. The bulk densities of the graphitic films are varied from 0.08 to $0.42 \mathrm{~g} / \mathrm{cm} 3$ dependent on the doping level (Table 1.). In addition, the capacitance performances of the graphite films prepared from the Bio-amylose are investigated using cyclic voltammetry and galvanostatic charge/discharge procedures. The potential utility of the carbonized and graphitized Bio-amylose films for supercapacitors was revealed. This approach may broaden the application and even the swill processing of polysaccharides.

Table 1. The summary of the relationships between iodine doping amounts, heat-treatment yields, and bulk density of A-900-V, A-900-L, and A-900-LV

\begin{tabular}{lcccc}
\hline & No iodine doping & A-900-V & A-900-L & A-900-LV \\
\hline lodine doping amount (mg) & - & $\sim 1.0$ & $\sim 1.0$ & $\sim 2.0$ \\
Doping time & - & 20 days & 3 days & $24 \mathrm{~h}$ \\
Carbonization yield (\%) & - (fused) & 20 & 25 & 30 \\
$\begin{array}{l}\text { Total graphitization yield (\%) } \\
\text { Bulk density of graphite film }\end{array}$ & - & 23 & 23 & 23 \\
$\left(\mathrm{~g} / \mathrm{cm}^{3}\right)$ & - & 0.42 & 0.1 & 0.08 \\
\hline
\end{tabular}




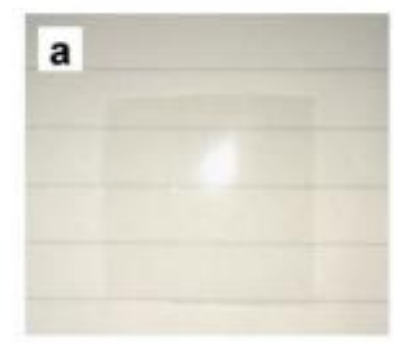

A-900

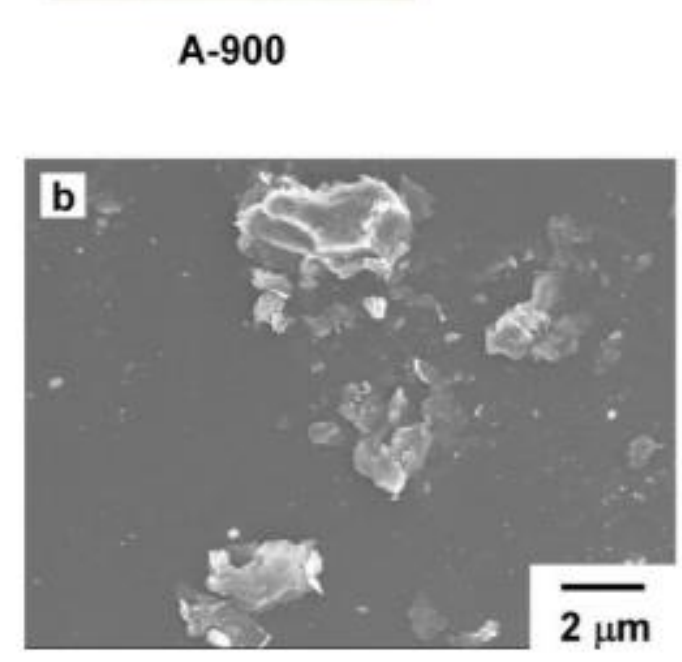

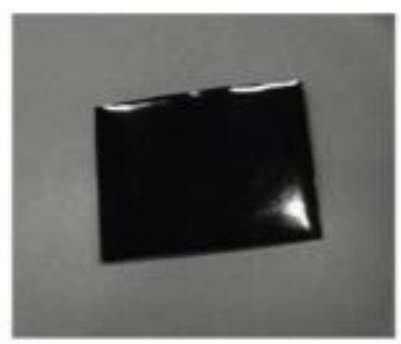

A-900-LV
: $2 / 1(\mathrm{v} / \mathrm{v})$

(5s)

\section{Vapor-phase iodine reaction}

(24 h)

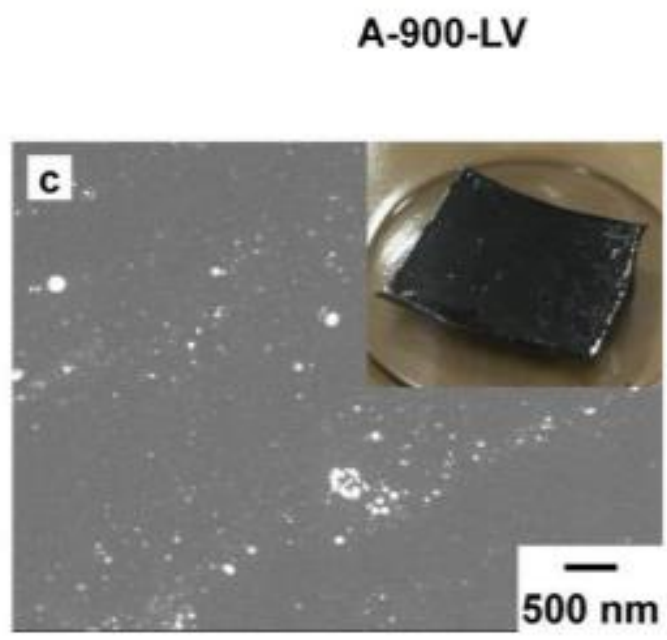

Figure 12. (a) Preparation of the A-900-LV iodine-doped amylose film. (b,c) SEM images of carbon films prepared from A-900-LV. The inset shows a photograph of the carbon film.
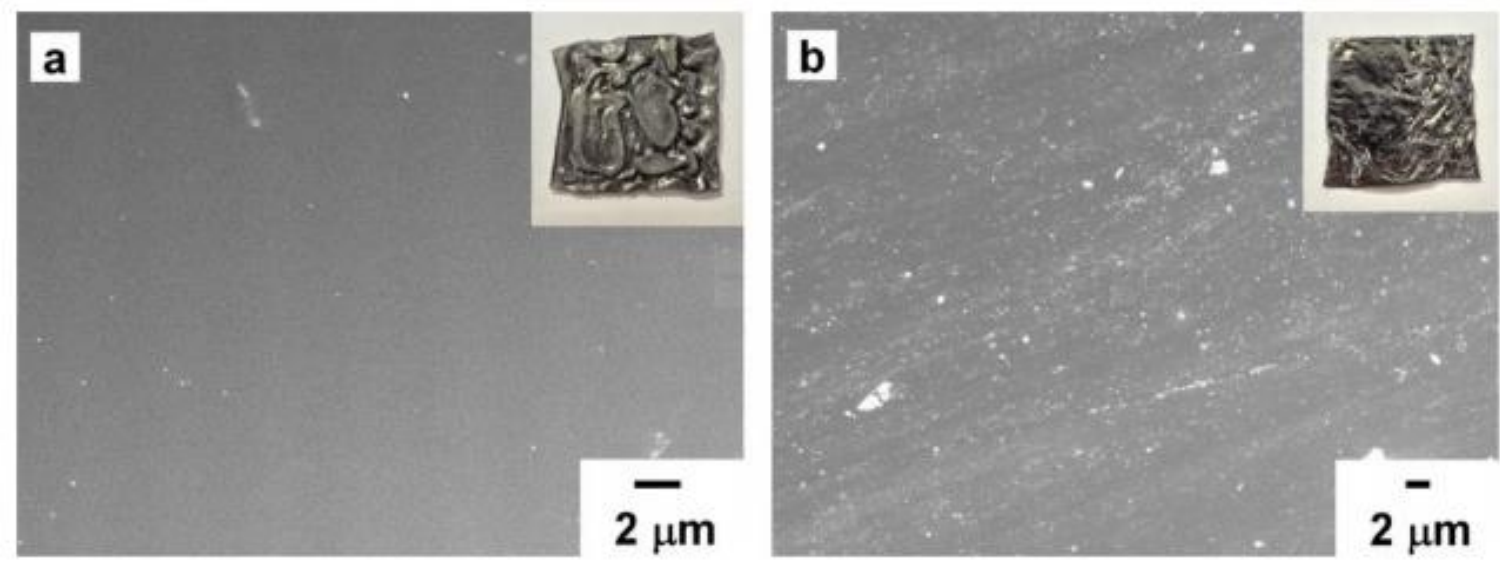

Figure 13. SEM images of carbon films prepared from (a) A-900-V and (b) A-900-L. The insets show photographs of the carbon films.

\section{Conclusions}

This review summarized the various industrial applications of polyiodide such as disinfectant, polarizing film, electrolyte and etc. We look forward novel applications of polyiodides to be developed in future. 


\section{Acknowledgements}

I would like to express my deepest appriciation to Dr. Takeshi Takaha and Dr. Nobuyuki Terada for their cooperation in the joint research of bio-amylose iodine and gratefully acknowledge Professor Kazuo Akagi and Professor Shinichi Kitamura for their cooperation in the joint research of low-density graphitic film.

\section{References}

1. Kaiho, T., lodine Made Simple, CRC Press, Taylor \& Francis: Boca Raton, FL, 2017. https://doi.org/10.1201/9781315158310

2. Kaiho, T. Eds., lodine Chemistry and Applications, John Wiley \& Sons: Hoboken, NJ, 2014. https://doi.org/10.1002/9781118909911

3. Mooney, R. C. L. Z. Krist.1935, 90, 143. https://doi.org/10.1524/zkri.1935.90.1.143

4. Kaiho T. Industrial production and Application of lodine. IDD Newsletter, February 2008, pp. 12-14.

5. Messier P.J. 2012. Facemask with filtering closure. US 8091551 B2.

6. Bourget, S.; Ohayon, D.; Tanelli, J.; Gendron, A.M.; Messier, P.J. Microbiocidal filtering media for individual protection: Facemasks and canisters. 8th International Symposium on Protection Against Chemical and Biological Warfare Agents, 2004, Gothenburg, Sweden.

7. Ohayon, D.; Bourget, S.; Gendron, A.M.; Tanelli, J.; Low, K.; Messier, P.J. Triosyn technology on the breakdown of chemical warfare agents and industrial chemicals in the workplace. The 9th Symposium on Iodine Utilization, October 24, 2006, Chiba University, Chiba, Japan.

8. Advanced NASA Technology Supports Water Purification Efforts Worldwide. February 29, 2012.

9. Goodwin, M.J.; Steed, B.W.; Yufit, D.S.; Musa, O.M.; Berry, D.J.; Steed, J.W. Cryst. Growth Des., 2017, 17 (10), 5552-5558. https://doi.org/10.1021/acs.cgd.7b01103

10. Inoue, O. ; Yoshikawa, M. ; Mieko Takaku, M. ; Kaiho, T. ; Mitsuru Taguchi, M. ; Sambe, H. ; Terada, Y. ; Takaha, T. US 9,206,531 B2 Dec. 8, 2015.

11. Synthetic Amylose : https://ps-biotec.com/english/product01.html

12. O’Regan, B.; Grätzel, M. Nature 1991, 353, 737. https://doi.org/10.1038/353737a0

13. Kunimasa, S.; Tasaki, M.; Yamada, H. ; Morimoto, S. ; Togai, M. Sumitomo Kagaku, Vol. 2012, Sumitomo R\&D report, pp. 1-10. https://www.sumitomo-chem.co.jp/english/rd/report/files/docs/03 2012e.pdf (accessed June 30, 2021).

14. Kogo, T.; Hayase, S.; Kaiho, T.; Taguchi, M. J. Electrochem. Soc. 2008, 155, K166-K169. https://doi.org/10.1149/1.2955722

15. Yana, B. ; Matsushita, S. ; Suzuki, S. ; Kitamura, S. ; Kaiho, T. ; Akagia, K. Carbohydrate Polymers 2018, 196, 15, 332-338.

https://doi.org/10.1016/i.carbpol.2018.05.050 


\section{Authors' Biographies}

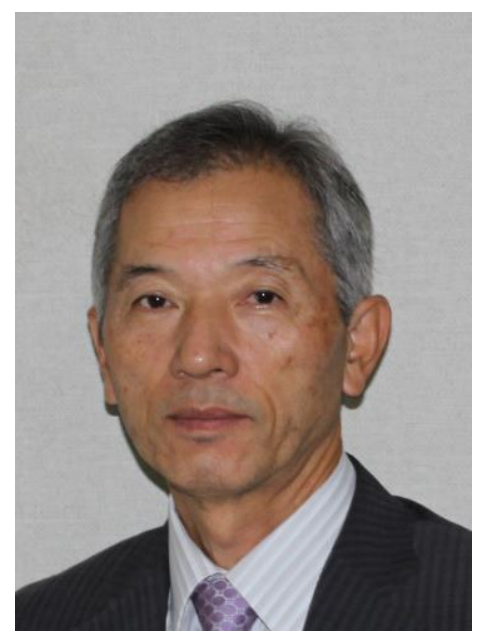

Tatsuo Kaiho is the Senior Advisor of Godo Shigen Co., Ltd. (Tokyo, Japan), one of the most well-known iodine manufacturing companies in the world. He is currently a visiting professor of Department of Science, Chiba University. He is a former Director of Nihon Tennen Gas Co., Ltd. (Chiba, Japan), and a former Director of Kanto Natural Gas Development Co., Ltd. (Chiba, Japan). The Director of the Society of lodine Science, Dr. Kaiho developed novel iodine-containing materials and processes and presented independent research at many conferences, including the 1st World lodine Association Conference (2017) and the Symposium of lodine Science (2017). Dr. Kaiho has received several awards, such as the Distinguished Chemist Award from Chiba Prefectural Government (2001), the Organic Synthesis Award from Society of Synthetic Organic Chemistry Japan (2002) and the Society of Iodine Science Award (2012). He organized the 4th International Conference of Hypervalent lodine Chemistry (2014) in Narita, Japan. Dr. Tatsuo Kaiho (born 1952) obtained his MSc (1976) from Osaka University. He joined Mitsui Chemicals Co., Ltd. in 1976. On leave from Mitsui, he worked as a visiting scientist at Massachusetts Institute of Technology (1979-1982) and obtained a PhD degree (1983) from Osaka University. From 2001-2003 he worked as a visiting professor at Department of Engineering of Chiba University. He is the editor of "Iodine Chemistry and Applications" and the author of "lodine Made Simple". 